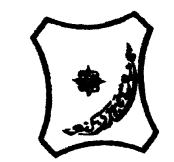

Bayero Journal of Pure and Applied Sciences, 12(2): 201 - 206

Received: October, 2019

Accepted: December, 2019

ISSN $2006-6996$

\title{
PREVALENCE AND PATTERN OF PAEDIATRIC NEUROLOGICAL DISORDERS MANAGED IN OUTPATIENT PHYSIOTHERAPY CLINICS IN KANO
}

\author{
Badaru, U.M., ${ }^{1}$ Ma'aruf, I.S., ${ }^{1}$ Ahmad, R.Y., ${ }^{1}$ Lawal, I.U., ${ }^{1}$ and Usman, J.S. $^{1}$ \\ ${ }^{1}$ Department of Physiotherapy, Faculty of Allied Health Sciences, Bayero University, Kano, Nigeria \\ Correspondence author: umbadaru.pth@buk.edu.ng OR badaruum@yahoo.com \\ Mobile: +2348035913759
}

ABSTRACT

Neurological disorders are among the major causes of physical disability in children. The aim of this study was to investigate the prevalence and pattern of Paediatric Neurological Disorders (PNDs) managed in outpatient Physiotherapy clinics in Kano. The 10-year retrospective descriptive study collected relevant data on PNDs from case files of the children who have been managed in Physiotherapy clinics of the 5 major referral hospitals in Kano using a data capture form. The population of children in Kano State based on the 2006 Census and the projected population for 2017 was obtained from the National Population Commission, Kano State office. The data obtained was analysed with descriptive statistics of mean, standard deviation, frequency and percentage. Data analysis was done using Microsoft excel and SPSS version 20. Results showed that 1927 paediatric cases were analysed out of which PNDs accounted for 1618 (83.96\%). The mean age of the children at the time of their first treatment visit was 3.13 years \pm 3.04 years (range $=33$ days-12years). Most of the children with PNDs are males 1101(57.1\%), with male to female ratio of 1.3:1. The Prevalence of PNDs in Kano was 0.257/1000 (i.e. 25.7/100,000). The most common PND that was managed by physiotherapists in Kano State was cerebral palsy which has a prevalence of $0.106 / 1000$ (i.e.10.6/100,000), (proportion $=41.16 \%$ ). It was concluded that PNDs are the most common paediatric cases managed by physiotherapists in Kano State with cerebral palsy having higher prevalence

Key words: prevalence, paediatric, neurological disorders, physiotherapy

\section{INTRODUCTION}

Neurological disorders are among the main causes of physical and mental disability, leading to limitations in the ability to perform wide variety of daily activities, including self-care, social interactions, mobility and communication (Raggi et al., 2015). The burden of neurological disability is more severe among children from low income countries (Kawakatsu et al., 2012) probably due to inadequate facilities or personnel in various relevant disciplines (Ofovwe and Ibadin, 2007) or owing to late presentation at the hospital (Frank-Briggs and Alikor, 2011). The management of Pediatric Neurological Disorders (PNDs) can be very expensive (Ofovwe and Ibadin, 2007) especially those PNDs that are chronic, progressive or lifelong (Canadian Institute for Health Information, 2007). Studies have shown that epilepsy, headache, stroke and intervertebral disc disorder are the common neurological disorders in adults (Onwuekwe and Ezeala-Adikaibe, 2011; Tegueu et al., 2013). On the other hand, the common
PNDs managed in the medical outpatient paediatric units are Cerebral Palsy (CP) 19.355.3\%, epilepsy 24.6-30.3\% (Ogbe et al., 2006; Ofovwe and Ibadin, 2007; Wammanda et al., 2007; Frank-Briggs and Alikor, 2011), central nervous system (CNS) infection 5.5-9.5\% (Ofovwe and Ibadin, 2007; Wammanda et al., 2007; Frank-Briggs and Alikor, 2011) and speech and language problems (Ogbe et al., 2006; Ofovwe and Ibadin, 2007). The PNDs that are commonly managed in the outpatient Physiotherapy clinics include CP 43.6-50.3\%, traumatic sciatic nerve injury 22.4-35.5\%, obstetric brachial plexus injury 8.9-13.3\%, neurological sequelae of CNS infections 5.7$8.1 \%$, radial nerve palsy $0.4-1.6 \%$ and facial nerve palsy $0.4-1.6 \%$ (Peters et al., 2008; Adelugba et al., 2011; Omole et al., 2013). Other conditions include: Down's syndrome 1.42.2\% (Peters et al., 2008; Omole et al., 2013), head injury, $1.4-1.6 \%$, and spinal bifida cystica 0.7-0.8\% (Adelugba et al., 2011; Omole et al., 2013). 
BAJOPAS Volume 12 Number 2, December, 2019

The Management of PNDs involves multidisciplinary team approach with Physiotherapist being an important member of the team (Peters et al., 2008). PNDs amenable to Physiotherapy management are usually associated with motor impairments that include muscle weakness, abnormal muscle tone, decrease in joint range of motion, balance and coordination (Peters et al., 2008; Omole et al., 2013) and in most cases, referral for rehabilitation could be due to delayed developmental milestone and inability to walk (Wammanda et al., 2007).

Regular evaluation of the prevalence and pattern of PNDs can be used to plan for future health service needs, allocate health care resources for the management of these disorders (Ofovwe and Ibadin, 2007; Danila et al., 2014), prioritize research expenditures, and raise public awareness about the impact of specific PNDs (Danila et al., 2014). Presently, there is paucity of published data on the pattern of the PNDs managed in outpatient Physiotherapy Clinics in Northern part of Nigeria. The aim of this study was to assess the prevalence and pattern of PNDs in Kano metropolis.

\section{MATERIALS AND METHODS}

The study was a 10-year retrospective descriptive survey. The case files of paediatric patients managed between $1^{\text {st }}$ April, 2007 and $1^{\text {st }}$ April, 2017 in the out-patient Physiotherapy Clinics of Aminu Kano Teaching Hospital (AKTH), Murtala Muhammad Specialist Hospital (MMSH), Mohammad Abdullahi Wase Specialist Hospital (MAWSH), and Hasiya Bayero Paediatrics Hospital (HBPH) were reviewed. Ethical approvals were obtained from the ethics committees of Aminu Kano Teaching Hospital (NHREC/21/08/2008/AKTH/EC/2030) and Kano State Ministry of Health for MMSH, MAWSH and HBWCH (MOH/OFF/797/T.I/384). The population of children in Kano State was obtained from the National Population Commission (NPC), Kano branch office (ref: NPC/OR/S/C/352). Relevant patient case files were obtained from the health record units and the following information were obtained: child's age, date of first treatment, diagnosis/impression, sex, date of onset of the condition, aetiology/risk factors, time between onset of disorder and commencement of physiotherapy and sources of referral.

\section{Assessment of the proportion and prevalence of PND}

1. Proportion of non-neurologic cases =

Total number of the non-neurologic disorders $x 100$

Total number of paediatric cases managed

2. Proportion of neurologic cases $=$

Total number of PND cases $x 100$

Total number of paediatric cases managed

Frequentist method was used for the determination of the prevalence of PNDs per 1000 of the population of children in Kano (Oskoui et al., 2013).

3. Prevalence of PND =

Total number of PND cases $\quad \times 1000$

Total population of children in Kano State

(Oskoui et al., 2013)

\section{Data analysis}

The data was analysed using descriptive statistics of mean \pm standard deviation, frequency and percentage using SPSS version 20.0 and Microsoft excel.

\section{RESULTS}

Socio-demographic characteristics of participants

The data of 1927 paediatric cases were analysed. The mean age of the children was 3.13 years \pm 3.04 years (range $=33$ days 12 years). Majority of the children are males $57.1 \%(n=1101)$, while females accounted for
$42.9 \%(n=826)$. PNDs accounted for 1618 cases $(83.96 \%)$ in which males constituted $57.4 \%$ $(n=928)$ and females constituted $42.6 \%$ $(n=690)$ with male to female ratio of $1.3: 1$ for PND (table 1). The time taken from the onset of the illness to the commencement of Physiotherapy is 15 months \pm 19.8 month (range $=3$ days to 3 years).

In this study non-neurological disorders accounted for 309 out of 1927 paediatric cases which gave a proportion of $16.04 \%$. Majority of the non-neurological disorders are orthopaedic $6.49 \%(n=125)$ and soft tissue and plastic $6.02 \%(n=116)$ cases. 
BAJOPAS Volume 12 Number 2, December, 2019 Pattern of PNDs

The most common PND in Kano metropolis is cerebral palsy (CP) with $41.16 \%(n=666)$, this was followed by delayed milestone $19.96 \%$ $(n=323)$, and hemiplegia $7.85(n=127)$ as presented in table 2.

\section{Prevalence of PNDs in Kano}

The total projected population of the children in Kano who are aged 0-14years was $6,288,321$ for year 2017 based on the data obtained from the NPC, Kano State Office. This gave the prevalence of PNDs in Kano as 0.257 per 1000 of the population (i.e. 25.7/100,000) based on the projected figures. The prevalence of $\mathrm{CP}$ in Kano metropolis was 0.106 per 1000 of population (i.e.10.6/100,000) based on the projected figures as presented in (table 3).

Table 1: Gender distribution for other paediatric disorders

\begin{tabular}{lccc}
\hline Condition & $\begin{array}{c}\text { Male } \\
\mathbf{n}(\%)\end{array}$ & $\begin{array}{c}\text { Female } \\
\mathbf{n}(\%)\end{array}$ & $\begin{array}{c}\text { Total } \\
\mathbf{n}(\%)\end{array}$ \\
\hline $\begin{array}{l}\text { PNDs } \\
\text { Non-neurological disorders }\end{array}$ & $928(57.4)$ & $690(42.6)$ & $1618(100)$ \\
Orthopaedic & & & \\
Cases with unknown diagnosis & $67(53.6)$ & $58(46.4)$ & $125(100)$ \\
$\quad$ Cardiopulmonary & $37(56.92)$ & $28(43.08)$ & $65(100)$ \\
$\quad$ Soft tissue & $2(66.7)$ & $1(33.3)$ & $3(100)$ \\
Total & $67(57.85)$ & $49(42.2)$ & $116(100)$ \\
& $1101(57.1)$ & $826(42.9)$ & $1927(100)$ \\
\hline
\end{tabular}

PNDs= Paediatric Neurological Disorders

Table 2: Pattern of paediatric neurological disorders managed by physiotherapists in Kano metropolis

\begin{tabular}{lcc} 
Neurological conditions & Frequency & Percent \\
\hline Paralysis of unspecified diagnosis & 20 & 1.24 \\
Poliomyelitis & 11 & 0.68 \\
Measles & 10 & 0.62 \\
CP & 666 & 41.20 \\
Downs syndrome & 38 & 2.35 \\
Paraplegia & 30 & 1.85 \\
Delayed milestone & 323 & 20.00 \\
Pott's diseases & 11 & 0.68 \\
Facial Nerve palsy & 41 & 2.53 \\
Meningitis & 86 & 5.32 \\
Hemiplegia ${ }^{+}$ & 127 & 7.85 \\
Cerebral malaria & 68 & 4.20 \\
Sciatic nerve palsy & 76 & 4.70 \\
Erb's palsy & 31 & 1.92 \\
Spina bifida & 20 & 1.24 \\
Head injury & 15 & 0.93 \\
Hydrocephalus & 15 & 0.93 \\
Other Peripheral nerve palsies & 11 & 0.68 \\
Guillein barre syndrome & 6 & 0.37 \\
Other neurological disorders* & 13 & 0.80 \\
Total & 1618 & 100
\end{tabular}

$\mathbf{C P}=$ Cerebral palsy, ${ }^{+}$the causes of hemiplegia presented above were not properly documented in patient case files as hemiplegia can arise from $\mathrm{CP}$, meningitis, head injury, stroke or sickle cell disease. *others disorders include: severe fatigue $=1$ case, psychiatric disorder with muscle weakness $=3$ cases, faecal incontinence $=2$ cases, Crouson's syndrome $=1$ case, aphasia=1case, William's syndrome $=1$ case and seizure with muscle weakness $=4$ cases 
BAJOPAS Volume 12 Number 2, December, 2019

Table 3: Prevalence of PNDs in Kano State

\begin{tabular}{|c|c|c|c|c|c|}
\hline $\mathbf{S} / \mathbf{N}$ & $\begin{array}{l}\text { Neurological } \\
\text { conditions }\end{array}$ & Frequency & $\begin{array}{l}\text { Prevalence per } 1000 \text { of } \\
\text { population based on } 2006 \\
\text { Census* }\end{array}$ & $\begin{array}{l}\text { Prevalence per } 1000 \text { of } \\
\text { population (based on } \\
2017 \text { population } \\
\text { projection) }^{+}\end{array}$ & $\begin{array}{l}\text { Prevalence per } \\
100,000 \text { of } \\
\text { population ( } 2017 \\
\text { projection) }\end{array}$ \\
\hline \multirow[b]{2}{*}{2} & \multirow{2}{*}{$\begin{array}{l}\text { Paralysis of } \\
\text { unspecified } \\
\text { Poliomyelitis }\end{array}$} & 20 & 0.0045 & 0.0032 & 0.32 \\
\hline & & 11 & 0.0025 & 0.0017 & 0.17 \\
\hline 3 & Measles & 10 & 0.0023 & 0.0016 & 0.16 \\
\hline 4 & $\mathrm{CP}$ & 666 & 0.1506 & 0.1059 & 10.59 \\
\hline \multirow{2}{*}{$\begin{array}{l}5 \\
6\end{array}$} & \multirow{2}{*}{$\begin{array}{l}\text { Downs syndrome } \\
\text { Paraplegia }\end{array}$} & \multirow{2}{*}{$\begin{array}{l}38 \\
30\end{array}$} & 0.0086 & 0.0060 & 0.6 \\
\hline & & & 0.0068 & 0.0048 & 0.48 \\
\hline 7 & Delayed milestone & 323 & 0.0730 & \multirow{2}{*}{0.0514} & 5.14 \\
\hline 8 & Pott's diseases & 11 & 0.0025 & & 0.17 \\
\hline 9 & Facial Nerve palsy & 41 & 0.0093 & 0.0065 & 0.65 \\
\hline 10 & Meningitis & 86 & 0.0194 & 0.0137 & 1.37 \\
\hline 11 & Hemiplegia $^{+}$ & 127 & 0.0287 & 0.0202 & 2.02 \\
\hline 12 & Cerebral malaria & 68 & 0.0154 & 0.0108 & 1.08 \\
\hline 13 & Sciatic nerve palsy & 76 & 0.0172 & 0.0121 & 1.21 \\
\hline 14 & Erb's palsy & 31 & 0.0070 & 0.0049 & 0.49 \\
\hline 15 & Spina bifida & 20 & 0.0045 & 0.0032 & 0.32 \\
\hline 16 & Head injury & 15 & 0.0034 & 0.0024 & 0.24 \\
\hline 17 & Hydrocephalus & 15 & 0.0034 & 0.0024 & 0.24 \\
\hline 18 & $\begin{array}{l}\text { Other Peripheral } \\
\text { nerve palsies }\end{array}$ & 11 & 0.0025 & 0.0017 & 0.17 \\
\hline 19 & $\begin{array}{l}\text { Guillein barre } \\
\text { syndrome }\end{array}$ & 6 & 0.0014 & 0.0010 & 0.10 \\
\hline 20 & $\begin{array}{l}\text { Other neurological } \\
\text { disorders* }\end{array}$ & 13 & 0.0029 & 0.0021 & 0.21 \\
\hline & Total PND & 1618 & 0.3659 & 0.2573 & 25.73 \\
\hline
\end{tabular}

$\mathrm{CP}=$ Cerebral palsy $*$ The population of children in Kano aged 0-14 years based on 2006 census was 4,422,452. 'the projected population of children for 2017 was 6, 288, 321.

\section{DISCUSSION}

Neurological conditions are among the main causes of physical and mental disability, leading to impairments at the level of different body functions (Raggi et al., 2015). It was observed in this study that male children had more PND than their female counterparts with male to female ratio of $1.3: 1$. This finding was interestingly the same with the outcome of prior studies in this area where it was found that male to female of 1.3:1 remain constant over the years (Peters et al., 2008; Lagunju and Okafor 2009; Adelugba et al., 2011) though higher male to female rations of up to $1.5: 1$ have however been reported in other studies (Wammanda et al., 2007; Frank-Briggs and Alikor, 2011; Omole et al., 2013).

In addition, this study found that PNDs accounted for over eighty percent $(83.96 \%)$ of the paediatric conditions managed by physiotherapists in Kano State within the last 10 years. This finding has confirmed the statement that paediatric neurological conditions are major workloads for Physiotherapy and rehabilitation in Nigeria (Omole et al., 2013). Studies have similarly reported that PNDs were the most common disorders that accounted for $83.6 \%$ of paediatric disorders (Peters et al., 2008). High proportions of $71.7 \%$ and $72.9 \%$ were also reported by Omole et al. (2013) and Adelugba et al. (2011) respectively. Lower prevalence of 6.7 and $21.0 \%$ have however been reported by the studies conducted in paediatric clinics by FrankBriggs and Alikor, (2011) and Lagunju and Okafor (2009) respectively. The possible reason for the high prevalence of neurological cases that are managed by physiotherapists could be because most of the paediatric cases referred for rehabilitation usually manifest with muscle weakness, delayed ability to achieve the required developmental milestone, abnormal muscle tone, decreased balance and coordination and reduced joint range of motion which are mostly associated with motor 
BAJOPAS Volume 12 Number 2, December, 2019 impairment due to neural pathology. This study observed that the PND with the highest proportion is CP with $41.20 \%$. This was followed by delayed milestone, hemiplegia, meningitis and sciatic nerve palsy in that order. CP cases are common in this study probably because among all the paediatric conditions, parents tend to be more proactive in taking children promptly to the hospital when there is obvious weakness that leads to the inability to hold their head erect, sit, stand or walk and in most cases the diagnosis of CP is usually made. Studies have also reported that $\mathrm{CP}$ cases accounted for $43.7 \%, 43.6 \%, 44.1 \%$ and $55.3 \%$ by Peters et al. (2008) Adelugba et al. (2011) Lagunju and Okafor (2009) and Wammanda et al. (2007) respectively.

The prevalence of PND based on 2006 Census and the projected 2017 population values are 0.366 and 0.257 per 1000 of the population of children of Kano respectively. Though the total number of PND is the same in both cases, but prevalence values differ due to the projected 1.42 fold increase in the total population of children in Kano without the corresponding projected increase in the number of children with CP. The implication of this finding is that, though total number of cases of PND may remain constant over the years; however, significant increase in the target population may show reduction in prevalence rate as observed in this study. This could be a limitation of the frequentist approach. In contrast to the findings of this research, a study reported that the prevalence of PND in Western Kenya was 29/1000 (Kawakatsu et al., 2012) and another

\section{REFERENCES}

Adelugba, J.K., Ayodiipo, I.O., Aladeyelu O, Ogunbameru, T.D., Oni, O.A., Akinsiku, O.A. and Akinremi, A. (2011): Paediatric Neurological Conditions Seen at the Physiotherapy Department of Federal Medical Centre, Ido Ekiti, Nigeria: A Five Year Review. African Journal of Biomedical Research 14(3):183-186

Canadian Institute for Health Information (2007): The Burden of Neurological Diseases, Disorders and Injuries in Canada. Ottawa: CIHI. Accessed at https://secure.cihi.ca/estore/productSeri es. $h$ tm?pc $=P C C 360$

Danila, O., Hirdes, J.P., Maxwell, C.J., Marrie, R.A., Patten, S., Pringsheim, T. and Jetté, N. (2014): Prevalence of neurological conditions across the continuum of care based on interRAI assessments. BMC Health Services Research, 14(29):1-14 reported $61 / 1000$ in the rural district of Kenya (Mung'ala-Odera et al., 2006). The possible difference in prevalence of PND between this study and those conducted in Kenya could be due to differences in population of people. Prevalence tends to be high in places with low population and the entire population of Western Kenya is 4.334 million (2009 Census) whereas the projected 2017 population of children alone in Kano State is over 6.288 million.

Finally the prevalence of $\mathrm{CP}$ is $0.150 / 1000$ based on 2006 Census and $0.106 / 1000$ based on the projected 2017 population of children alone in Kano state. Higher prevalence rate has been reported in an African community in which physical impairments accounting for 5/1000 (Kawakatsu et al., 2012).

\section{CONCLUSION}

It was concluded that neurological disorders are the most common paediatric cases managed by physiotherapists in Kano metropolis with $\mathrm{CP}$ having higher prevalence. The average time taken from the onset of the illness to the commencement of paediatric physiotherapy is 15 months. The prevalence of PND is $0.257 / 1000$ (i.e. $25.7 / 100,000$ ) and that of CP is $0.106 / 1000$ (i.e. 10.6/100,000) based on the projected 2017 population of children in Kano State.

\section{Authors' contributions}

All the authors have contributed equally in the design of the research, data collection and management, research report and proof reading.

http://www.biomedcentral.com/14726963/14/29

Frank-Briggs, A. I. and Alikor, E. A. D. (2011): Pattern of Paediatric Neurological Disorders in Port Harcourt, Nigeria. International Journal of Biomedical Science, 7 (2): 145-149.

Kawakatsu, Y., Kaneko, S., Karama, M., and Honda, S. (2012): Prevalence and risk factors of neurological impairment among children aged 6-9 years: from population based cross sectional study in western Kenya. BMC Pediatrics, 12 (186):1-8

http://www.biomedcentral.com/14712431/12/186

Lagunju, I.A., and Okafor, O.O. (2009): An analysis of disorders seen at the Paediatric Neurology Clinic, University College Hospital, Ibadan, Nigeria. West African Journal of Medicine, 28(1):3842. 
BAJOPAS Volume 12 Number 2, December, 2019

Mung'ala-Odera, V.1., Meehan, R., Njuguna, P., Mturi, N., Alcock, K.J., and Newton, C.R. (2006): Prevalence and risk factors of neurological disability and impairment in children living in rural Kenya. International Journal of Epidemiology, 35(3):683-688.

Ofovwe, G.E., and Ibadin, M.O. (2007): Pattern Of Neurological Disorders In Child Neurology Clinic Of The University Of Benin Teaching Hospital, Benin City, Nigeria. Annals of Biomedical Sciences, 6 (1): 18-27

Ogbe, Z., Nyarang'o, P., and Mufunda, J. (2006): Pattern of neurological diseases as seen in outpatient children: the experiences from Orotta Referral Hospital Asmara, Eritrea. Journal of Eritrean Medical Association, 1(1):11-15.

Omole, J.O., Olaogun M.O.B., and Mbada C.E. (2013): Pattern of Neurological Conditions Seen at the Outpatient Paediatric Physiotherapy Unit of a Nigerian Tertiary Hospital: A-five year review. Journal of Exercise Science and Physiotherapy, 9(2): 105-112.

Onwuekwe, I.O., and Ezeala-Adikaibe, B. (2011): Prevalence and distribution of neurological disease in a neurology clinic in Enugu, Nigeria. Annals of Medical and Health Sciences Research 1: 63-7.
Oskoui, M., Joseph, L., Dagenais, L., and Shevell, M. (2013): Prevalence of Cerebral Palsy in Quebec: Alternative Approaches. Neuroepidemiology, 40:264-268

Peters, G.O., Adetola A. and Fatudimu, M.B. (2008): Review of Paediatric Neurological Conditions Seen in the Physiotherapy Department of a Children's Hospital in Ibadan, Nigeria. African Journal of Biomedical Research, 11: $281-284$.

Raggi, A., Covelli, V., Leonardi, M., Meucci, P., Scaratti, C., Schiavolin, S., Willems, M., and Sattin, D. (2015): Determinants of disability using count-based approaches to ICF-based definition of neurological disability. NeuroRehabilitation, 36:2329.

Tegueu, C.K, Nguefack, S., Doumbe, J., Fogang, Y.F., Mbonda, P.C., and Mbonda, E. (2013): The spectrum of neurological disorders presenting at a neurology clinic in Yaoundé, Cameroon. Pan African Medical Journal, 14(148):16.

Wammanda, R.D., Onalo, R., Adama, S.J. (2007): Pattern of neurological disorder presenting at a paediatric neurology clinic in Nigeria. Annals of African Medicine, 6:73-75 